\title{
Assessing Wind Energy Conversion Systems Based on Newly Developed Wind Turbine Emulator.
}

\author{
Yasser E. Abu Eldahab*, Naggar H. Saad, Abdalhalim Zekry \\ Electrical Power and Machines, Faculty of Engineering, Ain Shams University, Cairo, Egypt \\ ( eng_yaser_hoseny@yahoo.com,naggar_hassan@yahoo.com, aaazekry@hotmail.com,.)
}

*Corresponding author Yasser E Abueldahab, eng_yaser hoseny@yahoo.com, Cairo, Egypt, 00201069470245

Received: 18.11.2020 Accepted:09.12.2020

\begin{abstract}
Wind energy has the fastest and highest growth rate of any other Renewable energy sources (RES). Investigating the Wind Energy Conversion Systems (WECS) is very important for improving efficiency. However, It is required a monumental accessible land space for installing Wind turbines(WT). Consequently, this paper presents the design and implementation of a Wind turbine emulator (WTE) to substitute WTs. The proposed WTE includes a new Maximum Point Power Tracking(MPPT) technique based on integrating binary search technique and genetic algorithm. The proposed emulator has an SQLite database as a repository of wind turbine information. Also, it has a graphical user interface(GUI) to facilitate the operation. System components have been modeled and simulated using MATLAB Simulink. Furthermore, a prototype is implemented based on a series excited DC motor and permanent magnet synchronous (PMSG). All static and dynamic characteristics have been investigated to prove the capabilities of the developed emulator. Also, an integration test has been conducted on real-time conditions of wind speed profile and working load for 24 hours to check the reliability. The experimental results are compared with the simulation results for validation and showed the capability of the proposed WTE of emulating a wide range of Wind turbines.
\end{abstract}

Keywords: Renewable energy systems, Wind Turbine Emulator; DC motor, Wind energy conversion systems, Genetic Algorithm.

\section{Introduction}

The latest renewable global status reports [1,2] show that Solar and Wind Power have the highest growth rate in RES during recent decades. Moreover, Wind Power installation capacity is more than $60 \%$ of the total capacity of all renewable energy sources. Therefore, researchers have been focusing on developing WECS in recent decades. However, researching wind power and investigations of the performance parameters of WECS require large space of available land for installing WECS, supporting components, many types of wind turbines with different attributes and orientations. WTEs can imitate efficiently static and dynamic behaviors of wind turbines in WECS and hence saving the required land space and supporting material and components. Also, they provide the ability to emulate divers wind turbines of different orientations and physical attributes. Furthermore, emulators can be integrated with a variety of electrical machines i.e induction, synchronous, and DC generators. Moreover, manufacturers of wind turbines can utilize such wind emulator as a tool to investigate all performance parameters of the developed turbines at different operating conditions. In [3], dozens of research contributions on Wind Power systems, have been reviewed and they showed that WTEs are very helpful in conducting researches on WECS without restrictions like dedicating massive land space, wind turbine orientation, size, and type of the connected electrical machines. Besides, they help researchers to investigate the performance parameters of WECS components including connected generators, power electronic devices, converters and inverters topologies, control techniques, optimization techniques, variable wind speed control techniques, MPPT algorithms et cetera. Furthermore, they can be used in laboratories to help students, engineers, and researchers in complementing the theoretical studies and researches with practical and experimental work like in [4]. Different machine types have been utilized as prime movers of WTEs like DC motors [58], Permanent magnet synchronous motors (PMSMs) [911], and Induction motors [12-15]. Table 1 lists some of the recent research contributions of developing WTEs showing the utilized machine type, control method, emulated characteristics, and range and size of the emulated turbines. It shows the DC motor is the most used in emulating wind turbines. Besides, most of them targeted a specific size of power rating and did not consider

Table 1 list of some research contributions in developing WTEs

\begin{tabular}{|lllll|}
\hline Reference & Machine & Control variable & Characteristics & Size of power \\
\hline $\mathbf{5}$ & DC Motor & Motor speed and torque & Dynamics & Variable and moderate \\
\hline $\mathbf{1 6}$ & DC Motor & Motor Speed & Statics & Fixed and small \\
\hline $\mathbf{1 7}$ & DC motor & Motor Current and Torque & Statics and Dynamics & Fixed and small \\
\hline $\mathbf{1 8}$ & AC induction motor & Motor speed & Statics & Fixed and small \\
\hline
\end{tabular}


INTERNATIONAL JOURNAL Of SMART GRID

Y. E. Abu Eldahab et al., Vol.4, No.4, December, 2020

\begin{tabular}{|lllll|}
\hline $\mathbf{1 9}$ & DC motor & Motor Torque & Statics & Fixed and small \\
\hline $\mathbf{2 0 - 2 1}$ & DC motor & Motor speed & Statics and Dynamics & Variable and small size \\
\hline $\mathbf{2 2 - 2 3}$ & DC motor & Pitch angle & Statics & Fixed and small \\
\hline $\mathbf{2 4 - 2 5}$ & AC induction motor & Motor Torque & Statics and Dynamics & variable and small \\
\hline $\mathbf{2 6}$ & AC induction motor & Motor speed & Statics and Dynamics & Variable and small \\
\hline $\mathbf{2 7}$ & AC Permanent Magnet Motor & Motor Speed & Statics & Fixed and small \\
\hline
\end{tabular}

The managing of the case of a variable wind speed or presenting an MPPT method. furthermore, a DC motor-based emulator has been introduced by [28]. Induction motor-based emulators were presented in [29]. Moreover, In [30], a complete WTE was presented based on a DC motor. They considered the different regions of wind speed. They counted for protecting of running at overrated power by utilizing pitch angle control. They used PSCAD software for simulating their system. Besides, the authors of [31] presented a complete simulation and experimental work of induction motor based WTE. They validated the theoretical and experimental results and verified the agreement between both results. Their prototype comprised an induction motor as a prime mover, PMSG, DC-DC boost converter, and Voltage Source control (VSC) inverter. Besides, in [32], the author presented the emulating system of the wind tunnel facility to experimentally investigate the performance parameters of wind turbines. They proposed their model aiming to help the manufacturers in their design of wind turbines. They focused on the TSR to power coefficient curve to extract the reference torque. Also, a real-time WTE has been introduced in [33] by using Labview and the national instrument CRIO platform. They developed their system based on PMSG and induction motor drive integrated with a direct torque control technique. To sum up the conducted review, there are many WTEs have been presented in literature which utilized a different type of electrical machines like induction, synchronous machine, and DC machines. The survey showed that the DC machine-based emulators are the best choice due to the simplicity of control and implementation and driving techniques. Most of the research contributions included simulation and a few of them included experimental implementation. Some considerations were not taken into considerations like restrictions of range limit of wind speed, management of operation at overrated power of generators. Therefore, this paper introduces a WTE that keeps the good features of the conventional WTEs and fixes their drawbacks. The design, simulation, and experimental implementation of the proposed system is presented. The proposed emulator is designed based on the series excited DC motor integrated with a speed-torque controller. Furthermore, the proposed emulator can manage efficiently different regions of operating conditions of wind speed including operating under the cut-in wind speed by enabling torque control technique as well as operation above the cut-out wind speed by enabling speed-torque control. The new emulator does not only can imitate a wider range of wind turbines than that of conventional emulators but also has additional competencies that make it a superior wind emulator. For example, it utilizes a new MPPT technique which is based on combining genetic algorithms and binary search technique for searching the MPP. Therefore, it is faster than traditional tracking techniques. Besides, a complete SQLite database is designed and built to store wind turbine information i.e. physical attributes radius, tower length, axis orientations, and the number of blades. Besides, it memorizes the optimum TSR at each wind speed values. Moreover, an awesome GUI has been designed to facilitate the operation and management of the proposed system to the end-users. Furthermore, the new emulator has the capability of remote monitoring and access control of all parameters of the systems like wind and rotor speed, torque, power of generator and motor, and voltages, currents, active and reactive power .. etc. The system has been modeled by using MATLAB Simulink, scripting, and application designer version $2018 \mathrm{~b}$. The system prototype is implemented based on coupling series excited DC motor and PMSG and controlled by using ARDUINO microcontroller. All static and dynamic characteristics of a wind turbine have been investigated and tested to verify the capabilities of the developed emulator. Unit tests and integration tests have been conducted including real-time variable wind speed profile and working loads for 24 hours. The simulation and experimental results are compared to verify and validate the proper operation of the new emulator and for investigating the performance parameters of the proposed system. The paper is organized as follows: Section 2 introduces the methodologies and system design; Section 3 discusses the results of the simulation as well as experimental work; Section 4 concludes the presented work.

\section{Methodology: \\ 2.1 Introduction}

This section introduces the mathematical model of the components of the proposed emulating system as well as presenting the experimental prototype components and the working principles of the proposed system.

\subsection{Wind Emulator System Modeling}

Fig. 1 shows the block diagram of the proposed wind emulator integrated with the generation unit. It comprises the GUI, SQLite Database, MPPT based Torque signal generator and control system, Wind turbine emulating unit, and Generation unit. In the following subsections, all these components are introduced in detail. 


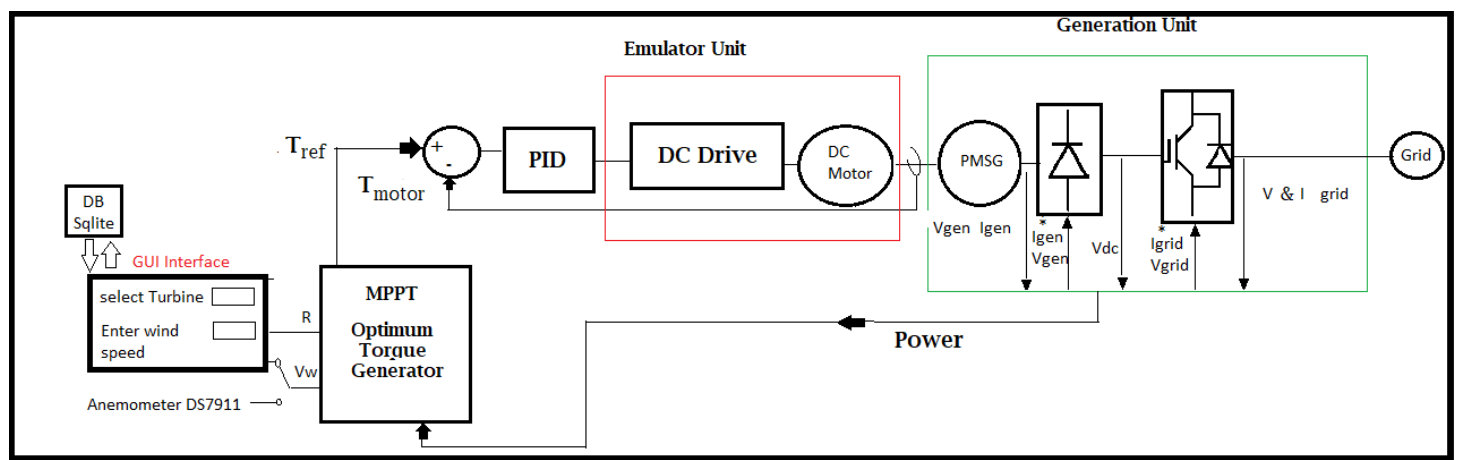

Fig. 1 System Block diagram

\subsubsection{SQ Lite Database}

For generalizing the proposed WTE, a relational database is a data repository of wind turbines related information and the optimum TSR values. Fig. 2 depicts the Entity-Relationship Diagram (ERD). The main table is called the Wind table which stores the turbine data like model part number, power capacity, number of blades and diameter, and description. Besides, there is a table called Wind_Speed which stores optimum wind TSR for each wind speed.

\begin{tabular}{|l|l|l|}
\hline \multicolumn{1}{|l|}{ Wind table } & Wind_speed \\
\hline Wind name & & Wind ID \\
wind ID & & Wind Speed \\
Wind power & & Opt_Lambda \\
Wind Diameter & & \\
Description & & \\
\hline
\end{tabular}

Fig. 2 The ERD system diagram

\subsubsection{GUI Interface}

For generalizing and facilitating the usage of the proposed emulator to the end-users, a GUI has been designed for helping users to select the turbine to be emulated, entering wind speed, ...etc. Fig. 3 shows the GUI main screen. It enables end-users to select any turbine from the list box. It also makes them entering data of wind speed as well as showing the specifications of the selected turbine and the matched TSR for specified wind speed. The GUI is a common component in simulation and experimental work. It passes the information from users to the model; besides, it sends data via serial communication port over RS232 to the microcontroller.

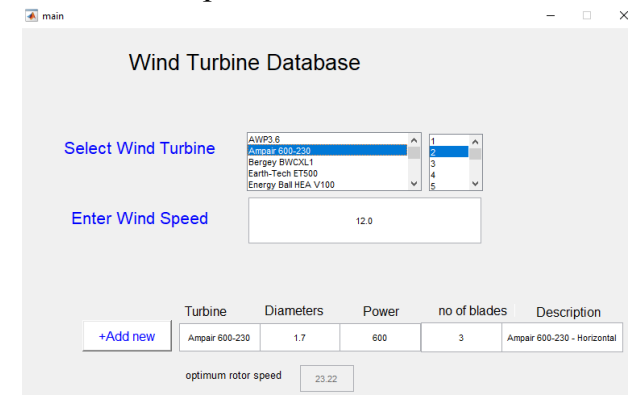

Fig. 3. The GUI interface

\subsubsection{The new MPPT for variable wind speed}

In [34-40], the authors conducted a comprehensive review of the tracking methods of WECS. They compared their performance parameters. They concluded that there are three commonly used methods. The first is called Optimum
Torque Control (OTC). And, two methods of Perturb and Observe ( $\mathrm{P} \& \mathrm{O}$ ). One is based on input voltage and the other is based on the duty cycle. Table 2 lists the concluded results of their review. The results show the superiority of the Optimum Torque Control (OTC) method in terms of power coefficient, response and recovery time, and efficiency. However, it depends on the turbine characteristics. Therefore, it is not flexible. The $\mathrm{P} \& \mathrm{O}$ methods are more flexible and easier for implementation. Nevertheless, they have an accuracy issue due to the noticed oscillations. Also, all these methods have an issue with sudden and fast changes in wind speed. Furthermore,

Table 2 comparison between MPPT methods in WECS

\begin{tabular}{|l|l|l|l|l|}
\hline $\begin{array}{l}\text { Tracking } \\
\text { Method }\end{array}$ & $\begin{array}{l}\text { Power } \\
\text { Coefficient }\end{array}$ & $\begin{array}{l}\text { Response } \\
\text { Time(s) }\end{array}$ & $\begin{array}{l}\text { Recovery } \\
\text { Time(s) }\end{array}$ & Efficiency \\
\hline OTC & 0.4789 & 0.02488 & 0.0006 & 90.66 \\
\hline $\begin{array}{l}\text { P \& O } \\
\text { (Input } \\
\text { Voltage) }\end{array}$ & 0.4607 & 0.053 & 0.0014 & 87.94 \\
\hline $\begin{array}{l}\text { P \& O } \\
\text { (Duty } \\
\text { Cycle) }\end{array}$ & 0.3965 & 0.2142 & 0.022 & 81.33 \\
\hline
\end{tabular}

Fig. 4 shows the case of sudden and fast change in wind speed from $10 \mathrm{~m} / \mathrm{s}$ to $12 \mathrm{~m} / \mathrm{s}$, in this case, the next step of O\&P may be in the wrong direction due to moving of the operating point from one power to speed curve to another curve due to the sudden change

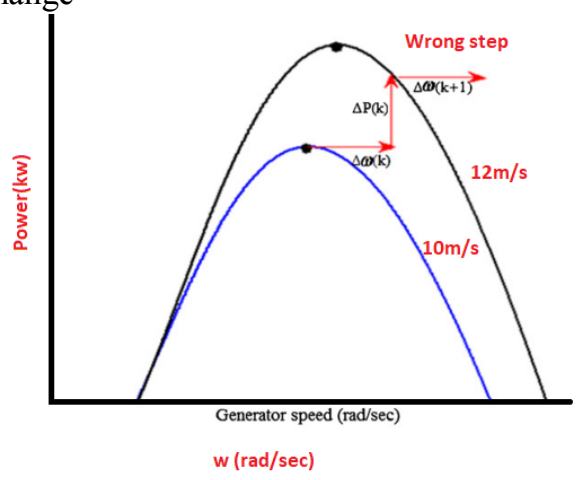

Fig. 4 The misleading in tracking the target due to sudden change in wind speed

in wind speed. The proposed emulator is integrated with a new method that utilizes the binary search techniques combined with a genetic algorithm to fetch the target MPP as 
in [41]. Fig. 5 shows an example in which the target MPP at point 4 and operation starts at point 1 . The nearest point to the target, which is point 2 , is determined thanks to utilizing the GA. Then it starts from point 2 and applies the binary search algorithm by dividing the search range into two parts and checking the slope of $\frac{d p}{d w}$ at the middle of the range which is at point 3 to decide the direction and update the start and the endpoints of the new search range. consequently, one part is discarded, and the other part is taken as the new search space. Again, it divides the new search domain into two parts and checks the slope of $\frac{d p}{d w}$ at the middle point. The process is repeated until the target is reached which is point 4 in this example. Furthermore, Fig. 6 shows the flow chart of the new MPPT technique. The process begins by reading the wind speed either from the received data by the GUI or from the anemometer sensor and reading the physical attitudes and parameters of the emulated turbine as well. Then it searches the database for the matched optimum rotor speed at which the output power is maxed. If there is a match, then it would be taken as a speed reference to drive the motor otherwise it calls the GA routine to determine the closest point to the MPP. This point is taken as the start point of the binary search process. The search continues as it is described above until fetching the MPP. It is then stored in the Database; besides, it is forwarded to the motor drive controller as a referenced speed.

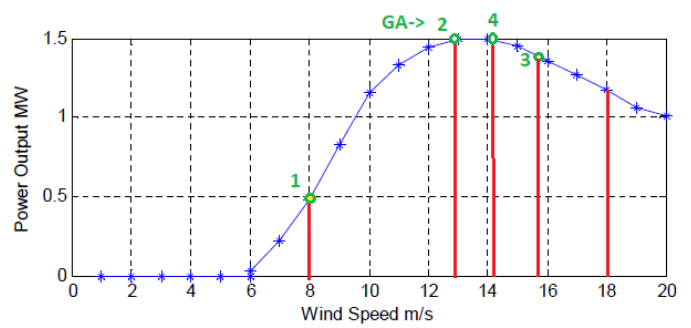

Fig. 5 Example of the proposed MPPT tracking steps

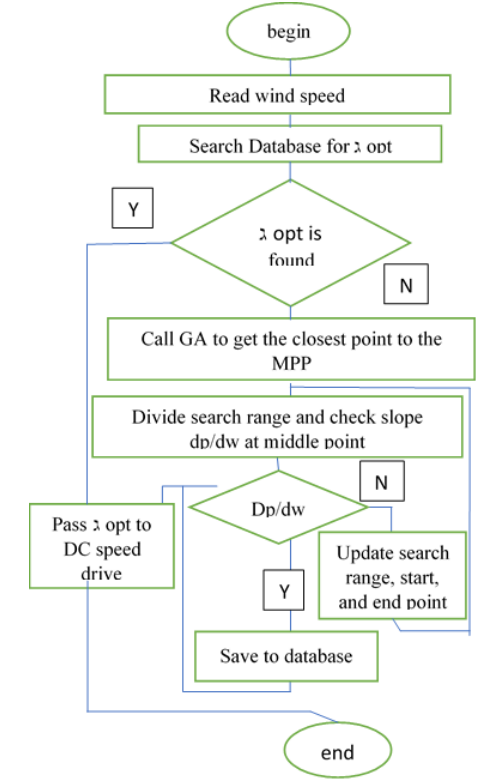

Fig. 6 Flowchart of the proposed MPPT speed control method

\subsubsection{DC motor and Speed-Torque drive submodel}

The main objective of WTE is to imitate static and dynamic characteristics of wind turbines which are represented in torque to speed and power to speed characteristics. Fig. 7 shows the sub-model of the DC motor and the closed-loop speed and torque controller as well. It shows inputs of the DC motor model which are the reference speed and torque. The reference speed is determined from the proposed MPPT and the torque is calculated based on the output power of the generation unit at a specific rotation speed. Therefore, the closed-loop control and the new MPPT technique guarantee that the motor is running at the desired speed and torque at which maximum power can be generated at a specific wind speed. The wind turbine is modeled and the DC motor-based emulator as well. Then all static and dynamic characteristics are studied and analyzed to realize that, the DC motor can successfully imitate the wind turbine.

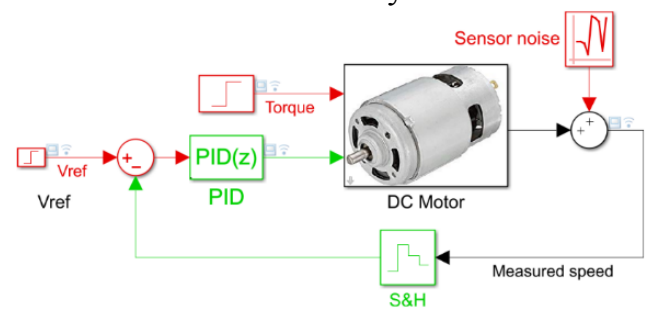

Fig. 7 Model of DC motor speed- Torque controller

\subsubsection{1 wind turbine model}

Although wind turbine is not a part of the proposed emulator model, its mathematical model is presented in this section to compare the results of the turbine model to that of the emulator model to verify that the proposed emulator can successfully imitate all turbine characteristics. The wind turbine mechanical power can be represented as follows [42]:

$P_{m}=\frac{1}{2} \rho \pi R^{2} v^{3} C_{p}(\lambda, ß)$

Where

$\rho$ : Density of Air.

R: Turbine Radius.

$C_{p}$ : Power Coefficient.

$\lambda$ : Tip speed Ratio.

ß: Blade pitch angle.

The power coefficient represents the efficiency of extracting power from a wind turbine. It is a nonlinear function of the blade pitch angle and the tip speed ratio and can be written as:

$C_{p}(\lambda, \beta)=0.5\left(116 \frac{1}{\lambda_{i}}-0.4 \beta-5\right) e^{-\left(21 / \lambda_{i}\right)}$

with

$\frac{1}{\lambda_{i}}=\frac{1}{\lambda+0.08 \beta}-\frac{0.035}{1+\beta^{3}}$

Where the tip speed ratio expresses the relation between the rotor speed $w_{m}$ to the wind speed $v_{w}$ as follows:

$\lambda=w_{m} R / v_{w}$

Where

$w_{m}$ : Rotor Angular Speed.

$v_{w}$ : Wind speed. 
By applying these model equations, the wind turbine static and dynamic characteristics can be determined as shown in Fig. 8. It shows the optimum speed dashed curve that represents the optimum speed at which the extracted power is maximum for each wind speed. In this configuration, the pitch angle is fixed to zero. Therefore, the power coefficient, in this case, becomes a function in the tip speed. The controller aims to adapt the tip speed at the optimum value at which it produces the maximum power.

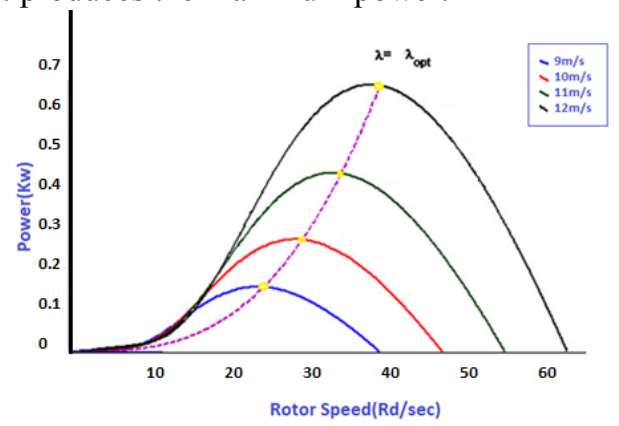

Fig. 8 Power speed characteristics of the wind turbine

\subsubsection{DC motor model}

A series type DC motor is utilized in the proposed emulator. In such type, the field and armature windings are connected in series and supplied by one DC source. Besides, the magnetic flux is directly proportional to the armature current as follows:

$\Phi=\mathrm{c} I_{f}=\mathrm{c} I_{a}(5)$

Where

$\Phi:$ The produced magnetic flux

$I_{f}, I_{a}$ : Field and Armature Current.

There are three main characteristics of a DC motor as follows:

I- Torque versus armature current:

The developed torque can be calculated as follows:

$T_{\text {dev }}=K \phi I_{a}$ (6)

By using 5 , it can get the following:

$T_{\text {dev }}=K I_{a}^{2}$ (6)

Equation (6) shows that the developed torque is proportional to the square of armature current.

II- Speed versus armature current:

By taking KVL of the typical circuit of series DC motor, it yields the following:

$V_{s}=E_{a}+I_{a}\left(R_{a}+R_{s}\right)$

With

$E_{a}=K c I_{a} W_{m}$

Where

$R_{A}, R_{s}:$ Armature and series resistances

$E_{a}:$ EMF induced voltage.

By solving 7 and 8 , the relation between speed and armature current can be expressed as follows:

$W_{m}=\frac{V_{s}}{K c a}-\frac{R_{a}+R_{s}}{K c}(9)$
III- Torque versus speed characteristics:

By solving eq. 6 and 9, the relation between speed and torque can be expressed as follows:

$W_{m}=\frac{V_{S}}{\sqrt{k c} \sqrt{T_{\text {dev }}}}-\frac{R_{A}+R_{S}}{K c}(10)$

By conducting the mathematical analysis above of the DC motor, the three main characteristics of the DC motor can be formulated, and they can be used in testing and discussing the results to show how the DC motor can realize all static and dynamic characteristics of the wind turbine.

\subsubsection{PMSG Modeling}

Although the generator is not a basic component of the proposed wind emulator, it is mathematically modeled to be used later in conducting an integration test of the developed emulator. The PMSG has been chosen due to its high efficiency, easy interface, lightweight, high reliability, power density, self-excitation, and gearless construction. Its model represents a permanent magnet synchronous machine that can work as a motor or a generator. The mode of operation is requested by the sign of the mechanical torque (positive for motor and negative for generator). This is a sinusoidal model that assumes the established flux of the permanent magnet is sinusoidal and the automotive force as well. The $\mathrm{d}-\mathrm{q}$ frame representation of the three-phase electrical system can be expressed as follows [43]:

$\frac{d i_{d}}{d t}=\frac{1}{L_{d}} v_{d}-\frac{R}{L_{d}} i_{d}+\frac{L_{q}}{L_{d}} p w_{m} i_{q}(11)$

$\frac{d i_{q}}{d t}=\frac{1}{L_{q}} v_{q}-\frac{R}{L_{q}} i_{q}-\frac{L_{d}}{L_{q}} p w_{m} i_{d}-\frac{2 p w_{m}}{L_{q}}$ (12)

$T_{e}=1.5 p\left(i_{q \lambda}+\left(L_{d}-L_{q}\right) i_{d} i_{q}\right)(13)$

Where

$i_{d}, i_{q}, V_{q}, V_{d}, L_{d}, L_{q}$ : The currents, voltages, and inductances of the $d$ and $q$ axis of PMSG

$T_{e}$ : Electrical Torque.

The phase inductance between phase $\mathrm{a}$ and $\mathrm{b}$ when phase $\mathrm{c}$ is opened can be represented as a function of the inductances of $\mathrm{d}$ and $\mathrm{q}$ axis and the rotor position as follows:

$L_{a b}=L_{d}+L_{q}+\left(L_{q}-L_{d}\right) \cos \left(2 \theta_{e}+\frac{\pi}{3}\right)$

Where

$\theta_{e}$ : Electrical angle

\subsubsection{The Generator and power electronics submodel}

Fig. 9 shows the generation sub-model which is coupled with the DC motor-based wind emulator model. It also includes the power electronics subsystems including rectifying, converting, and inverting sections. As shown in Fig. 9, the sub-model consists of the model of the PMSG, universal bridge that rectifies the AC output of the generator to DC voltage, DC link, Diodes based universal bridge rectifier. PWM IGBT inverter, LC filter, and measurement devices. The DC motor speed and torque are controlled so that the coupled generator produces maximum power. 


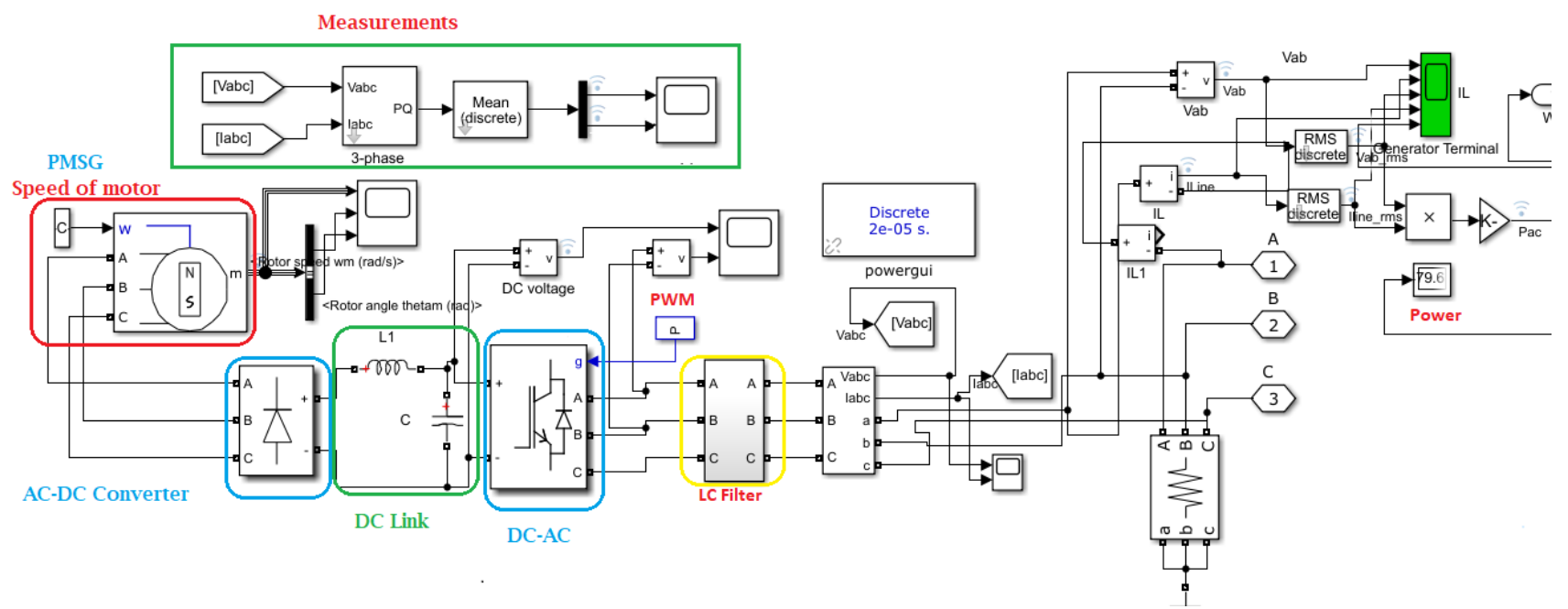

Fig. 9 Model of Wind emulator-based wind generator

\subsection{System prototype}

Fig. 10 shows the block diagram of the system prototype circuitry. It is composed of an Atmel 8-bit AVR microcontroller that receives analog signals of current and voltages of generator and grid output signals, DC voltage of the DC link as well. Besides, it receives the torque signal of motor generator coupling. It is responsible for calculating the generated power and calculating the reference torque and speed. Besides, it generates switching pulses for motor drive, converter, and inverter at generation and grid side. Also, the system includes a series of exited dc motors, PMSG. Furthermore, it includes an LCD which can display 2 lines of 16 characters/. Also, the system includes many sensing and measurement devices i.e current and voltage sensors 0-10 VDC, Anemometer DS7911 .. etc.

\subsubsection{Working principles}

The microcontroller receives the turbine attributes and the sensed wind speed and direction by using an anemometer ds7911. It then searches the database to fetch the optimum TSR thanks to the new MPPT proposed technique.

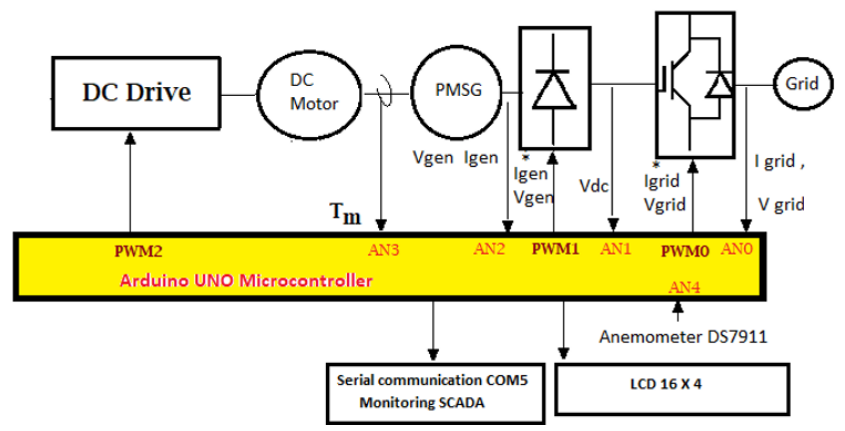

Fig. 10 Block Diagram of the proposed WTE prototype

Table 3 The BOM of the proposed wind emulator

\begin{tabular}{|l|l|l|}
\hline Component & Description & Count \\
\hline DCM & $\begin{array}{l}\text { DC motor of 200W power } \\
\text { rating, Supply voltage 12VDC, } \\
\text { Speed up to 15000RPM }\end{array}$ & 1 \\
\hline PMSG & $\begin{array}{l}\text { Permanent magnet miniature } \\
\text { generator of 200W, 50HZ,220v, }\end{array}$ & 1 \\
\hline
\end{tabular}

Also, it calculates the optimum torque based on the feedback power signals by which the system can generate the maximum power. The controller generates switching pulses based on the reference signals of torque and speed to the motor drives. Also, it generates the switching pulses for rectifying and inverter circuits. Furthermore, the microcontroller sends all metrics of measured parameters of rotating speed, torque, current, voltage, and power values to the serial port to enable users to monitor system parameters during the operation rather than displaying the most important metrics on the LCD screen. Furthermore, the controllers enable the pitch control by tuning the motor speed based on the received feedback of the power signals. If the power is going to exceed the rating power, the controller reduces the motor speed so that generator works up to its rating power all the time. Table 3 lists the bill of material (BOM) including components of the proposed prototype. Besides, Fig. 11 photographs the emulator experimental setup showing the emulator coupled engines of motor and generator on the left. Also, it images the control circuit as well.

\begin{tabular}{|l|l|l|}
\hline & $\begin{array}{l}\text { and 0.85 power factor, speed } \\
\text { range1500-10000 RPM }\end{array}$ & \\
\hline $\begin{array}{l}\text { Battery 12v } \\
\text { 100AH }\end{array}$ & 12V Battery of 100AH capacity & 1 \\
\hline $\begin{array}{l}\text { SQL 50A } \\
1000 \mathrm{v}\end{array}$ & $\begin{array}{l}\text { Three-phase bridge rectifiers of } \\
\text { 50A and 1000V rating. }\end{array}$ & 1 \\
\hline L9110 & Dual motor speed drive & 1 \\
\hline Speed sensor & Motor shaft encoder & 1 \\
\hline LCD1604 & LCD 16 X 4 & 1 \\
\hline $\begin{array}{l}\text { Arduino } \\
\text { UNO R3 }\end{array}$ & $\begin{array}{l}\text { Atmel 8-bit AVR } \\
\text { microcontroller }\end{array}$ & 1 \\
\hline DS7911 & $\begin{array}{l}\text { Anemometer for measuring } \\
\text { wind speed and direction }\end{array}$ & 1 \\
\hline
\end{tabular}




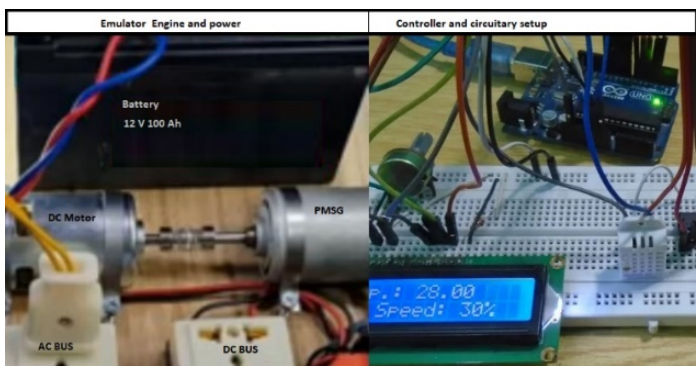

Fig. 11 Experimental setup of the proposed system.

\section{Results and discussion}

\subsection{Introduction}

In this section, the results of the simulation and experimental work are presented and discussed. Unit and integration tests are conducted in simulation and experimental work as well. In the unit test, the proposed wind emulator is tested separately without engaging with the generation unit to determine its performance parameters and ability to imitate static and dynamic characteristics of a wind turbine. In the integration test, the proposed emulator is tested as a part of complete WECS by coupling with the PMSG to study the performance of the emulator in a real WECS environment. Test cases of simulation and experiment work include different operating conditions i.e. variable wind speed, different types of turbines of different static and dynamic attributes and characteristics.

\subsection{Simulation results}

\subsubsection{Unit test cases}

\subsubsection{Testing WTE model characteristics}

This test verifies and validates the static and dynamic characteristics of the turbine model and the emulator model as well. Figures 12 and 13 depict the characteristics of power to a rotor speed of the wind turbine model and the proposed emulator model at different wind speeds.

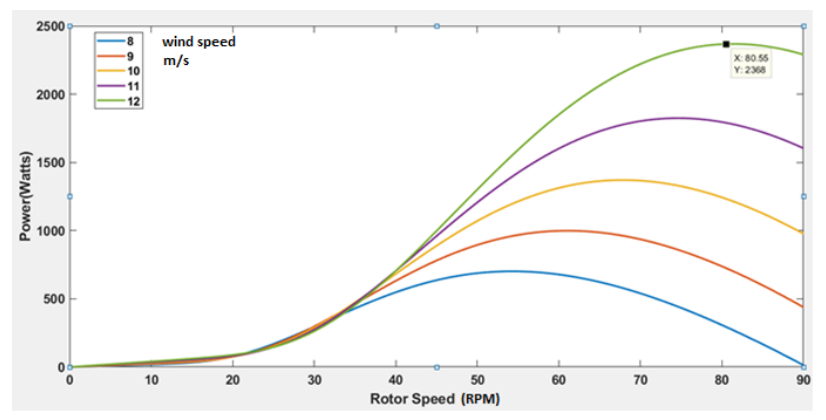

Fig. 12 Turbine model Power to Speed C/Cs test at different wind speed

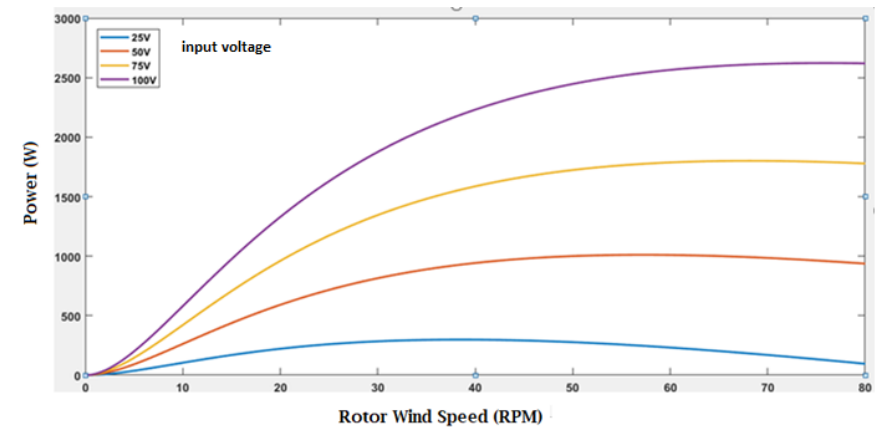

Fig. 13 Power to Speed C/Cs of the WTE model at different field voltage or speed

\subsubsection{Testing the speed and torque control of the} proposed emulator

After verifying the ability of the DC motor-based emulator model of imitating properly the characteristics of the wind turbine, this test is conducted to show the torque and speed control at variable wind speed. The user selects a turbine to be emulated i.e. AMPAIR 600-230 and the wind speed as well thanks to the GUI interface as shown in Fig. 3. The wind speed is set to be changed from i.e. $10 \mathrm{~m} / \mathrm{s}$ to be i.e. $12 \mathrm{~m} / \mathrm{s}$ at a time ( $\mathrm{T}=3$ seconds). The Proportional Integral Derivative (PID) control is utilized to follow the reference speed and torque. The PID parameters are tuned based on manual calculations which are verified with the MATLAB PID tuning facility. The best tuning parameters were found to be (Proportional $(\mathrm{P})=142.57$, Integral $(\mathrm{I})=288.25$, and Derivative $(\mathrm{D})=11.15)$. Fig. 14 and 15 show the results of testing the speed and torque control. They show that the reference speed has been followed rapidly and accurately.

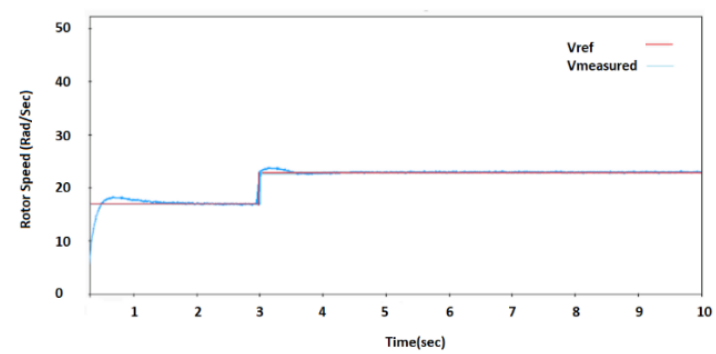

Fig. 14 Testing the speed control of the proposed emulator.

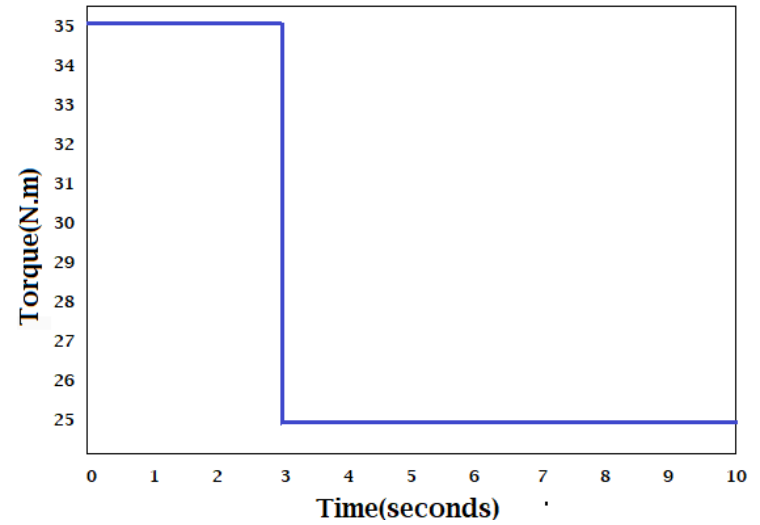

Fig. 15 Changes of torque relevant to speed changes 


\subsubsection{Testing the new MPPT algorithm}

In this test case, the system is run under the control of the traditional $\mathrm{P} \& \mathrm{O}$ tracking algorithm and the new MPPT technique as well. Fig. 16 shows the results of the traditional $\mathrm{P} \& \mathrm{O}$ on the left curve and the results of the new MPPT algorithm on the right. The new proposed algorithm reaches the target MPP in few iterations while the conventional $\mathrm{P} \& \mathrm{O}$ takes hundreds of iterations to fetch the target point. Besides, the new algorithm minimizes the ripple and more accurate than the traditional technique.
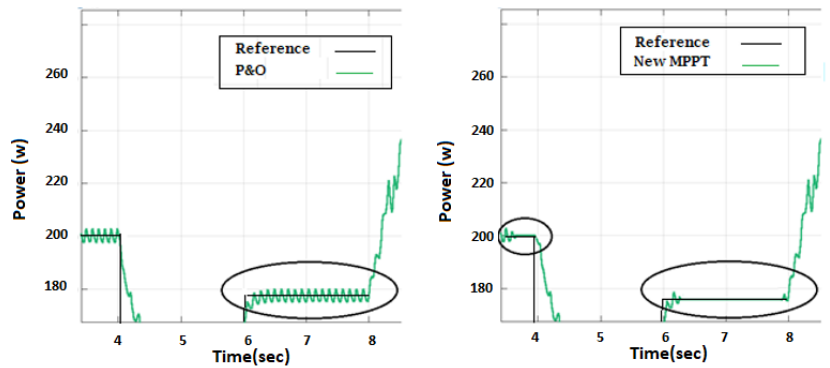

Fig. 16 The traditional and new MPPT method

\subsubsection{Integration test}

After testing the proposed emulator as a standalone unit, in this integration test of the developed emulator, the torque, speed, power, and other electrical measurements of the complete WECS system including the motor, generator, and connecting components are presented. In this test, the AMPAIR 600-230 wind turbine is selected to be emulated at the condition of having the wind speed changed at the time ( $\mathrm{T}=1$ second) from $8 \mathrm{~m} / \mathrm{s}$ to $12 \mathrm{~m} / \mathrm{s}$. Fig. 17 and 18 present the DC and AC line voltage and current at a different speed. Also, Fig. 19 depicts the generated power of the WECS system at different speed values. By comparing with the nominal power of the emulated wind turbine, It can be noticed the high efficiency of the proposed emulator shows $96 \%$. thanks to the accuracy of the proposed emulator model and the new MPPT method.

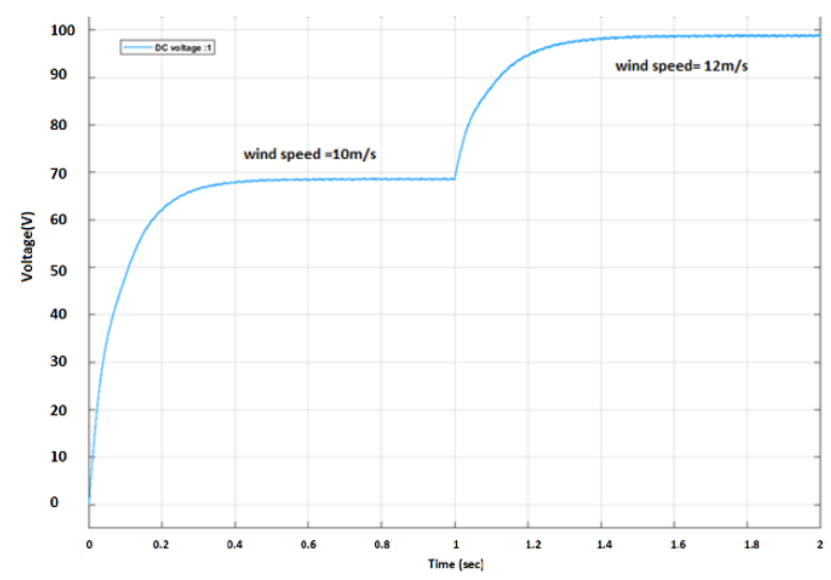

Fig. 17 DC voltage of DC link at different wind speeds.

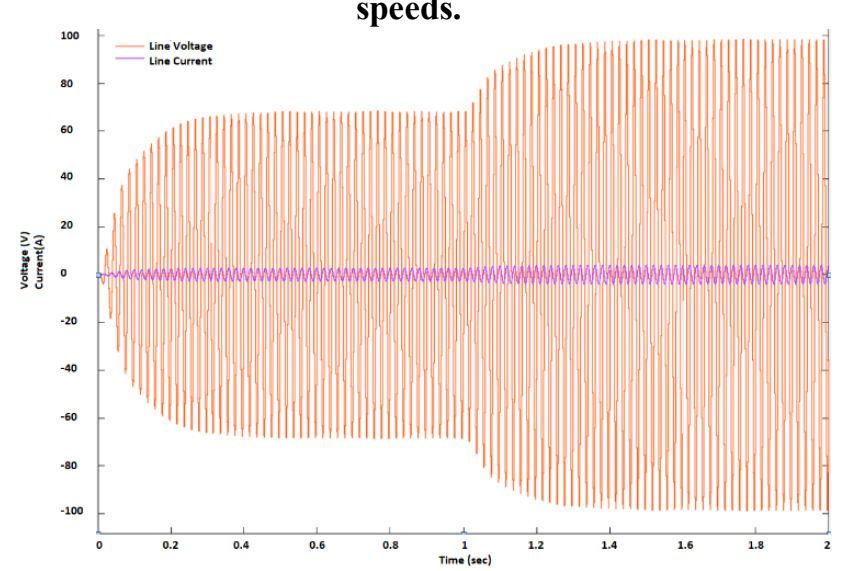

Fig. 18 AC voltage and current at different wind speeds.

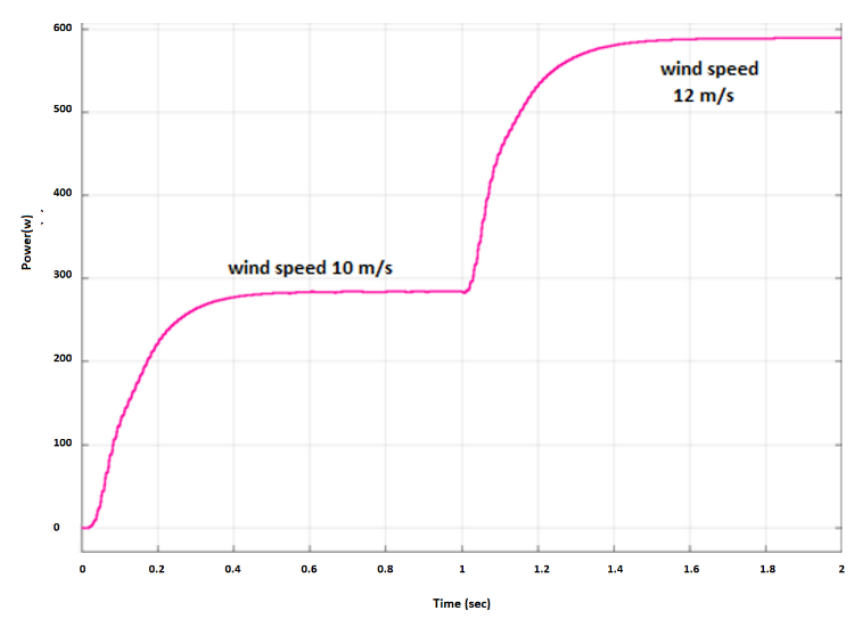

Fig. 19 The generated power at different wind speeds.

\subsubsection{Integration test of real-time condition}

To verify the reliability of the proposed emulator, a real-time condition has been simulated in this test. Fig. 20 depicts the wind speed profile during the complete day. Also, fig. 21 shows the 24 hours load profile represented in the orange curve. Also, it depicts the output power of the wind emulator during the whole operation time represented by the green curve. Furthermore, it shows the grid output power through the operation period. It also shows the grid power is negative indicating that the excessive power of the wind power has been exported to the grid. The test result shows the capability of stable and proper operation of the proposed emulator during a long period with variable load and wind speed profile. 


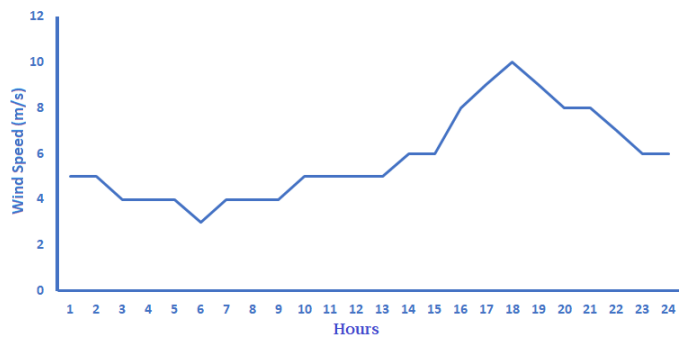

Fig. 20 The wind speed profile of the complete day.

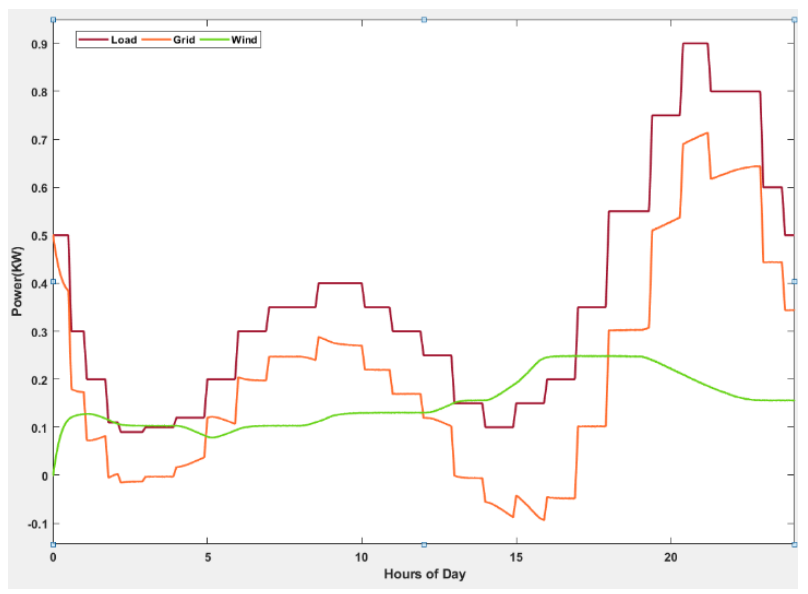

Fig. 21 The real-time integration test of the WTE

\subsubsection{Cut-in and Cut-off test}

In this test, the emulator behavior at cut-in and cut-off wind speed is verified. Fig. 22 depicts a wind speed profile which includes a cut-in speed (2 $\mathrm{m} / \mathrm{s}$ ) at time duration from 3 am to 5 am and cut-off speed $(12 \mathrm{~m} / \mathrm{s})$ at time duration from $4 \mathrm{pm}$ to $6 \mathrm{pm}$. The results are shown in Fig. 23. It shows the proposed emulator enables the torque control at the time of running under cut-in wind speed while it enables the pitch angle control at the time of working above the cut-off wind speed. Consequently, it can manage both cases and works up to the designed power rating in case of higher wind speed and stops generations at lower wind speed.

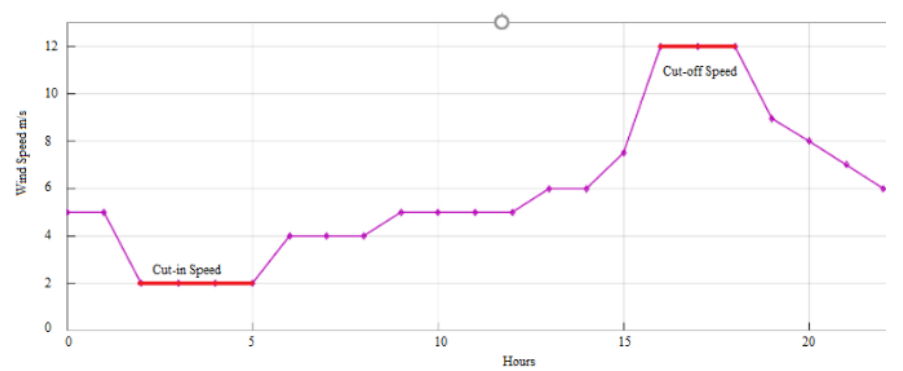

Fig. 22 The wind speed profile.

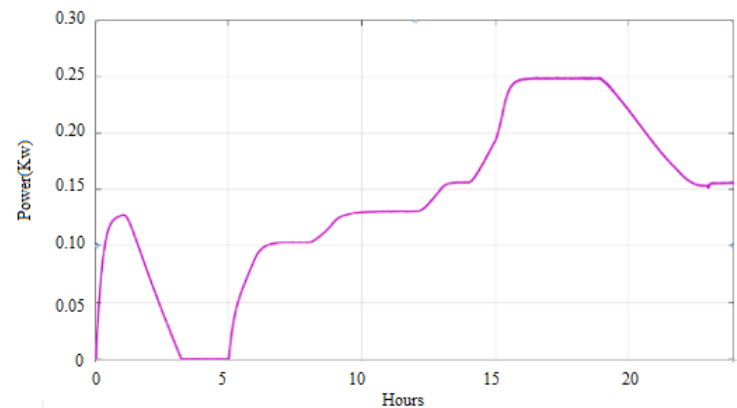

Fig. 23 The output power of the proposed WTE at Cut-in and Cut-off wind speed.

\subsection{Experimental results}

\subsection{1 unit test}

This test examines the control of speed and torque of the emulator experimentally to prove the ability to imitate the wind turbine. The used DC motor speed range is up to 15000 RPM. By using the GUI interface shown in Fig. 3, the user can select a wind turbine to be emulated and the operating wind speed as well. The system then fetches the optimum TSR and in turn the optimum rotor speed and torque either from the database or by invoking the new MPPT algorithm. This test case imitates the performance of a wind turbine when wind speed changes from $10 \mathrm{~m} / \mathrm{s}$ to $12 \mathrm{~m} / \mathrm{s}$. Fig. 24 presents the measured and logged data of speed, torque, current, and voltage of the DC motor thanks to the proposed feature of serial communication and data transfer through the COM port using the microcontroller. It shows clearly that, the speed is governed at a specific rotation speed which is the optimum rotor speed for maximizing the generated power. Besides, Figures 25 and 26 depict the speed and torque of the DC motor at different operating conditions of wind speed.

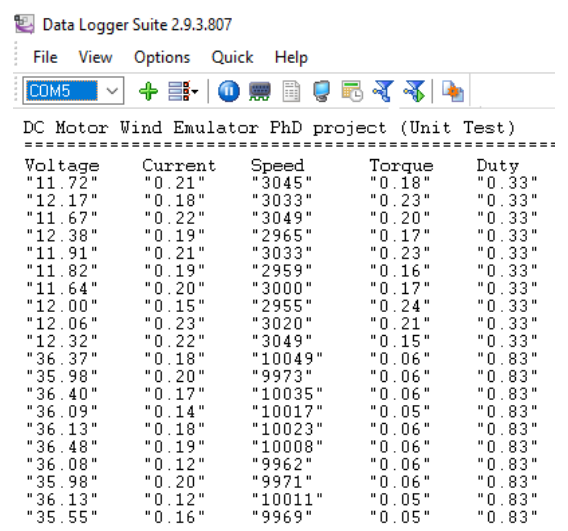

Fig. 24. The logged and measured DC motor speed

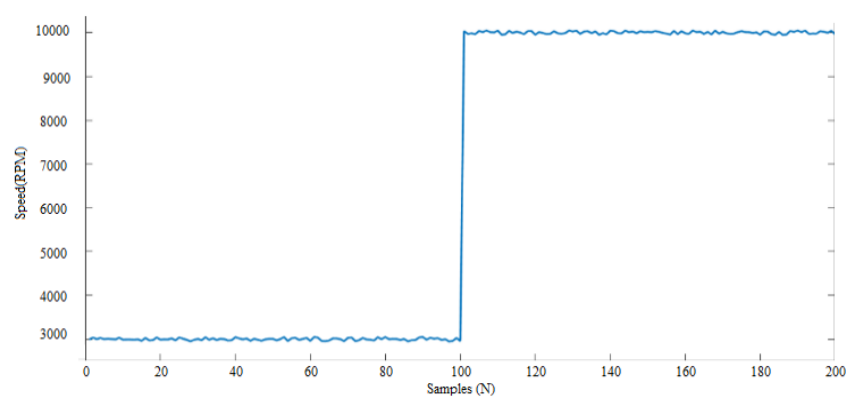

Fig. 25 The speed control of the DC motor 


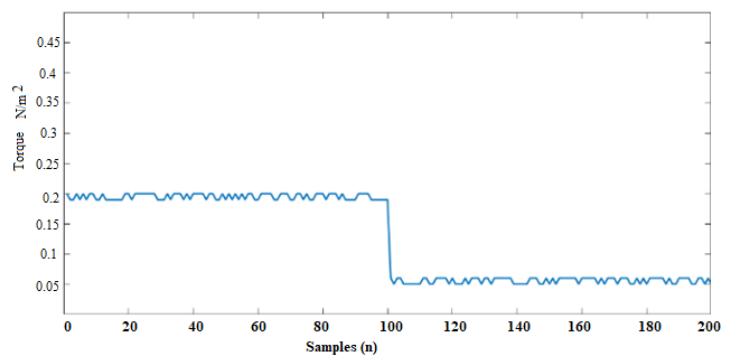

Fig. 26 Torque control of the DC motor

\subsubsection{Integration test}

In this test, a complete WECS system including the DC motor, miniature PMSG, and power electronic subsystems are tested to verify and validate the performance of the proposed emulator. Fig. 3 is used as a GUI interface to set the test parameters i.e. the operating wind speed and selecting the emulated wind turbine. Consequently, the system fetches the optimum TSR and reference rotor speed and torque thanks to the new proposed MPPT and the lookup database. All test results are logged and reported to the com port as shown in Fig. 27. It shows the motor voltage, current, rotating speed, and torque. Also, it reports the output voltages at generator terminals, the rectified voltage at the DC link, and the input and output power.

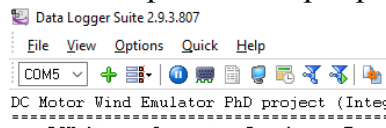

\begin{tabular}{|c|c|c|c|c|c|c|c|c|}
\hline DCVol tage & Current & & Torque & & & & & \\
\hline $\begin{array}{l}=12.27 " \\
" 11.74 "\end{array}$ & $\begin{array}{l}n 0.13 " \\
" 0.14 "\end{array}$ & $\begin{array}{l}n=13 " \\
n 302010\end{array}$ & $\begin{array}{l}0.19 " \\
n=0.20 "\end{array}$ & $\begin{array}{l}0.33 " \\
" 0.333 "\end{array}$ & $\begin{array}{l}" 73.11 " \\
" 73.26 "\end{array}$ & "105.46" & 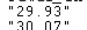 & $\begin{array}{l}25.1 \\
-25.1\end{array}$ \\
\hline$" 11.76 "$ & " $0.13 "$ & 年 29950 & $=0.20 "$ & "0.33" & $" 76.280 "$ & "102.15" & $\begin{array}{l}30.09 " \\
" 29.79 " 1\end{array}$ & "25 \\
\hline "11.67" $" 11.85 "$ & $\begin{array}{l}0.14 " \\
" 0.14 "\end{array}$ & "2959," & $\begin{array}{l}0.20 " \\
" 0.20\end{array}$ & $\begin{array}{l}0.33 " \\
" 0.33 "\end{array}$ & $\begin{array}{l}74.30 " \\
" 73.77 "\end{array}$ & $\begin{aligned} & 99.80 " \\
& " 102.94 "\end{aligned}$ & $\begin{array}{l}30.07 " \\
" 29.93 "\end{array}$ & \\
\hline $\begin{array}{l}72 " \\
47 " \\
47\end{array}$ & $" 0.13 "$ & $\begin{array}{l}2954 " \\
" 3049 "\end{array}$ & $=0.20 "$ & $\begin{array}{l}0.33 " \\
" 0.33 "\end{array}$ & $\begin{array}{l}\text { "70.49" } \\
770.03 "\end{array}$ & 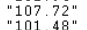 & $=0.30 .36 " "$ & \\
\hline $\begin{array}{l}47^{\prime \prime} \\
26^{\prime \prime}\end{array}$ & $\begin{array}{l}00.14 " \\
0.13 "\end{array}$ & " $29954 "$ & $=0.19 "$ & $0.33 "$ & " $73.46 "$ & "101.03" & $\begin{array}{l}29.85 " 1 " \\
" 29.51 "\end{array}$ & \\
\hline "11.89" & " $0.14 "$ & " $29711 "$ & $\begin{array}{l}0.20 " \\
" 0.060 "\end{array}$ & $\begin{array}{l}0.33 " \\
" 0.83 "\end{array}$ & $\begin{array}{l}" 79.70 " \\
" 232\end{array}$ & 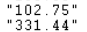 & $\begin{array}{l}30.48 " \\
" 46.14 "\end{array}$ & \\
\hline $36.17 "$ & $" 0.11 "$ & "10044" & $" 0.06 "$ & "0.83" & $" 232.27 "$ & "336.84" & $" 45.82 "$ & \\
\hline $\begin{array}{l}36.50 " " \\
36.38 "\end{array}$ & 11 & "10043" & $0.06 "$ & "0.83" & 230 . & & "46.43" & \\
\hline $35.61 "$ & & "9954" & $0.06 "$ & 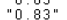 & 8.86 & & 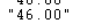 & \\
\hline $43^{\prime \prime}$ & 5" & $10009 "$ & & $0.83 "$ & 9 & & 45.5 & \\
\hline & & 99996 & & . 83 . & & & & \\
\hline 然 & & $\begin{array}{l}1.9969 \\
.9969\end{array}$ & 0 & 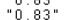 & & & 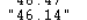 & \\
\hline
\end{tabular}

Fig. 27 log data of integration test

Fig 28 displays the line voltage measured by the USB oscilloscope and shows the RMS values and the THD as well. Also, the logged values of the line voltage and rectified voltage are depicted in Fig. 29.

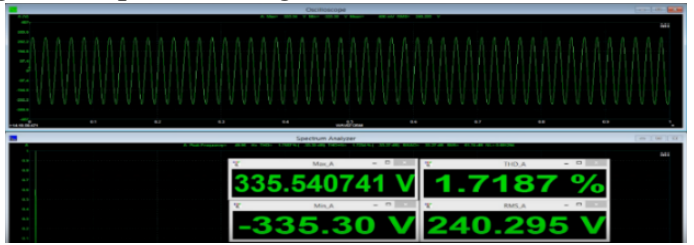

Fig. 28. The line voltage output of the PMSG at 10000 RPM

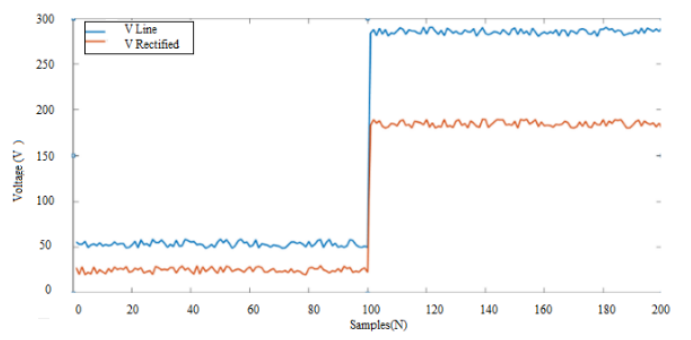

Fig. 29 Line voltage changes with speed changes
Fig. 30 compares the input power of the DC motor and the output power of the WECS. It shows an efficiency of $96 \%$ which is within the acceptable range.

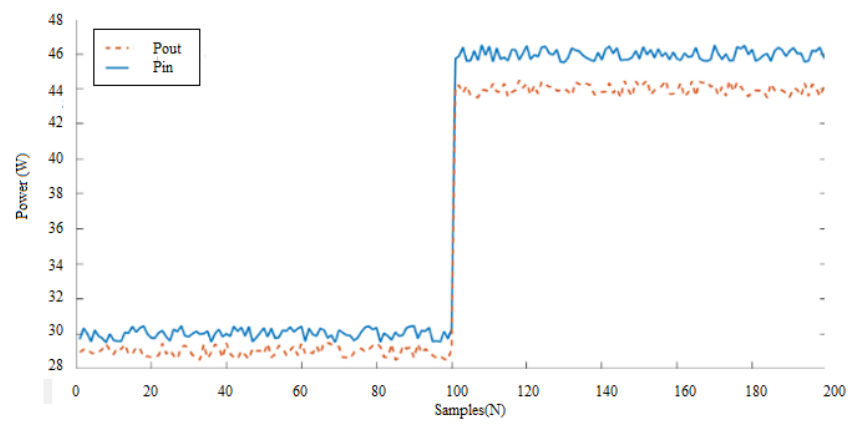

Fig. 30 Output power from the generator versus the input power of the DC motor

\subsubsection{Integration real-time test}

In this test, a real-time operation of the complete day has been conducted to verify the stability of the proposed emulator. Fig. 31 shows the load profile in red color, the wind output power in blue color, and the grid output power in purple color. The proposed emulator can provide power during the whole duration and compatible with the wind profile during the period of operation. Also, it shows the grid imports and exports power based on the output power of the emulator and the load power.

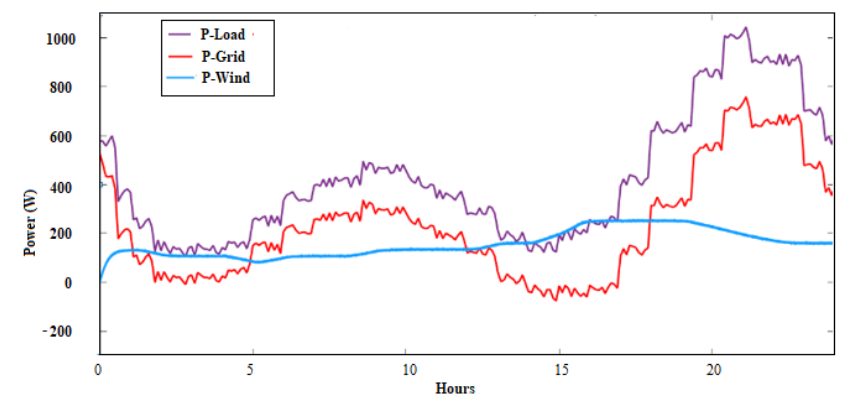

Fig. 31 Real-time test of the proposed emulator

\section{Conclusions}

Reviewing the recent official renewable energy statistics and reports showed the superiority of wind energy source in installation capacity and growth rate in the last decades. Therefore, developing WECS is of the most interest of renewable energy researches. However, investigating the performance parameters of WECS requires massive accessible land space for installing wind turbines in addition to related supporting components. So, Wind emulators can play a suitable replacement of wind turbines in academic studies and researches for assessing and developing WECS. Consequently, this paper reviews the recent researches of developing WTEs comparatively to collect the advantages and good features to be included and the existing drawbacks to be avoided in the next generation of WTEs. It then presents a novel WTE that has many add-ons. Firstly, It can efficiently manage the cut-in and cut-off wind speed conditions by enabling torque control and pitch angle control methods respectively. Consequently, it governs the generator to work up to its power rating and avoiding running at very low wind 
speed. Also, it increases the range of limited power and hence the variety of emulated turbines. Furthermore, It has an awesome GUI that facilitates the operation and management of the whole system to the end-users. Also, it utilizes a novel MPPT method which is designed based on a genetic algorithm combined with a binary search technique that accelerates the speed of fetching the MPP. The mathematical model of the proposed WTE is simulated by using MATLAB Simulink 2018 and showed identical results to that of the standard wind turbine model. Also, A prototype of the proposed WTE has been implemented based on coupling series excited DC motor with miniature PMSG and controlled by using an Atmel 8-bit AVR microcontroller. The experimental results have been compared with the simulation results for validating the success and accuracy of the developed emulator. The proposed emulator has been examined as a standalone system by running unit tests to determine the static and dynamic characteristics and the simulation and experimental results showed that the proposed emulator can imitate a wide range of wind turbines. The results showed high accuracy and efficiency reached $96 \%$ and fast response to the sudden change in wind speed thanks to utilizing the newly proposed MPPT technique. Also, Integration tests have been conducted to examine the developed emulator in a complete WECS at fixed and variable wind speed as well. Furthermore, a real-time test has been conducted by running the proposed emulator in real WECS conditions including variable speed wind profile and the variable load of the complete day. The simulation and experimental results were aligned together and showed accurate and reliable performance and fast convergence of the proposed emulator. As a result, the developed emulator can be considered as a tool for helping students, researchers, and wind turbine manufacturers in investigating the performance parameters, assessing, and developing WECS and wind turbine manufacturing.

\section{References}

[1] Renewables 2018 Global status report http://www.ren21.net/ (last accessed on December 12, 2020) [2] International electricity agency report 2017 http://www.iea.org (last accessed on December 12, 2020)

[3] Y. AbuEldahab, A. Zekry, N. Saad, Enhancing the Optimization of Hybrid Renewable Energy Systems by Using Statistical Calculations and Data Mining Analysis, IJRER, Vol 9, No 2 (2019), PP 868-886

[4] S. Ozcira, N. Bekiroglu, and A. Agcal, "A study on feasibility of wind energy production in Silivri region by using laboratory setup", International Conference on Renewable Energy Research and Applications (ICRERA), Madrid, Spain, 20-23 Oct. 2013, 1175 - 1179

[5] T. Hardy W. Jewell. Hardware-in-the-loop wind turbine simulation platform for a laboratory feeder model. IEEE Trans Sustain Energy 2014;5(3):1003-9.

[6] O. KY, L. JK, B. HJ, P. JY, L. JS, E. BI. Development of a $20 \mathrm{~kW}$ wind turbine simulator with similarities to a $3 \mathrm{MW}$ wind turbine. Renew Energy2014;62:379-87.
[7] A. Dahbi, M. Hachemi, N. Nait-Said, M. Nait-Said. Realization and control of a wind turbine connected to the grid by using PMSG. Energy Conversion and Management, 2014;84:346-53.

[8] S. Abdeddaim, A. Betka, S. Drid, M. Becherif. Implementation of MRAC controller of DFIG based variable speed grid connected wind turbine. Energy Conversion and Management, 2014;79:281-8.

[9] N. Averous, M. Stieneker, S. Kock, C. Andre, A. Helmedag, R. Doncker, Development of a $4 \mathrm{MW}$ full-size wind-turbine test bench. IEEE J Emerg Sel TopPower Electron 2017;5(2):600-9.

[10] J. Yan,Y. Feng, J. Dong. Study on dynamic characteristic of wind turbine emulator based on PMSM. Renew Energy 2016;97:731-6.

[11] Y. Daili, J. Gaubert, L. Rahmani. Implementation of a new maximum power point tracking control strategy for small wind energy conversion systems without mechanical sensors. Energy Conversion and Management 2015;97:298306.

[12] J. Castello, J. Espi, R. Gil. Development details and performance assessment of a wind turbine emulator. Renew Energy 2016;86:848-57.

[13] A. Sajadi, L. Roslaniec, M. Klos, P. Biczel, K. Loparo. An emulator forfixed pitch windturbine studies. Renew Energy 2016;87:391-402.

[14] L. Gan, J. Shek, M. Mueller. Modeling and characterization of downwind tower shadow effects using a wind turbine emulator. IEEE Trans Ind Electron2017;64(9):7087-97.

[15] L. Gan, J. Shek, M. Mueller. Analysis of tower shadow effects on battery lifetime in standalone hybrid wind-dieselbattery systems. IEEE Trans Ind Electron2017;64(8):623444.

[16] M. Chinchilla, S. Arnaltes, J. Rodriguez-Amenedo. Laboratory set-up for wind turbine emulation. In: Proc. IEEE International Conference on IndustrialTechnology (ICIT'04) 8e10 Dec. 2004. p. 553e7. Hammamet-Tunez.

[17] M. Monfared, H. Kojabadi, H. Rastegar. Static and dynamic wind turbine simulator using a converter controlled dc motor. Renew Energy 2008;33(5):906e13.

[18] R. Teodorescu, F. Blaabjerg. Flexible control of small wind turbines with grid failure detection operating in standalone and grid-connected mode. IEEETrans Power Electron 2004;19(5):1323e32.

[19] R. Cardenas, R. Peña. Sensorless vector control of induction machines for variable-speed wind energy applications. IEEE Trans Energy Conv 2004;19(1):196e205. [20] D. Ramirez, S. Martinez, F. Blazquez, C. Carrero. Use of STATCOM in wind farms with fixed-speed generators for grid code compliance. Renew Energy2012;37:202e12.

[21] J. Zaragoza, J. Pou, A. Arias, C. Spiteri, E. Robles, S. Ceballos. Study and experimental verification of control tuning strategies in a variable speed wind energy conversion system. Renew Energy 2011;36:1421e30.

[22] M. El Mokadem, V. Courtecuisse, C. Saudemont, B. Robyns, J. Deuse. Experimental study of variable speed wind generator contribution to primary frequency control. Renew Energy 2009;34:833e44.

[23] J. Arribas, C. Veganzones, F. Blázquez, C. Platero, D. Ramírez, S. Martínez, Computer-based simulation and scaled 
laboratory bench system for theteaching and training of engineers on the control of doubly fed inductionwind generators. IEEE Trans Power Syst 2011;26(3):1534e43.

[24] H. Kojabadi, L. Chang, T. Boutot. Development of a novel wind turbine simulator for wind energy conversion systems using an inverter-controlled induction motor. IEEE Trans Energy Conv 2004;19(3):547e52.

[25] I. Munteanu, N. Cutululis, A. Bratcu, E. Changa. Optimization of variable speed wind power systems based on a LQG approach. Control Eng Pract 2005;13(7):903e12.

[26] R. Cárdenas, R. Peña, P. Wheeler, J. Clare, G. Asher. Control of the reactive power supplied by a WECS based on an induction generator fed by a matrix converter. IEEE Trans Ind Electron 2009;56(2):429e38.

[27] D. Dolan, P. Lehn. Real-time wind turbine emulator suitable for power quality and dynamic control studies. In: Proc. International Conference on Power Systems Transients (IPST'05) 19e23 Jun. 2005. p. 1e6. Montreal-Canada.

[28] B. Rabelo, W. Hofmann, M. Gluck. Emulation of the Static and Dynamic Behavior of a Wind-turbine with a DCMachine. The 35th Annual IEEE Power Electronics Specialists Conference. 2004:2107-2112.

[29]J. Wu and Y. Xu, Dynamic wind-turbine emulation based on induction motor [J]. Journal of South China University of Technology.2005, (6):46-49

[30] J. Vaheeshan, A. Atputharajah, "Wind Turbine Emulator", 2011 6th International Conference on Industrial and Information Systems, ICIIS 2011, Aug. 16-19, 2011, Sri Lanka

[31] A. Sokolovs, L. Grigans, E. Kamolins, J. Voitkans, An Induction Motor Based Wind Turbine Emulator, Latvian Journal of Physics and Technical Sciences, 2014, No 2, DOI: 10.2478/lpts-2014-0009

[32] I. Camilo. M. Martínez, D. Jackson. T. Twizere, D. Lundback-Mompó, S. Orts-Grau, J. Francisco. G. Sales and S. Seguí-Chilet, Small Wind Turbine Emulator Based on Lambda-Cp Curves Obtained under Real Operating Conditions, Energies 2019, 12, 2456; doi:10.3390/en 12132456

[33] M.1 Topor, Wind Turbine Emulator Development Using Labview FPGA, International Journal of Emerging Engineering Research and Technology, Volume 3, Issue 7, July 2015, PP 13-21.

[34] M. Abdullah, A, Yatim, C. Tan, R. Saidur, A review of maximum power point tracking algorithms for wind energy systems, Renewable and Sustainable Energy Reviews 16 (2012) 3220-3227

[35] M. Allouche, S. Abderrahim, H. Ben Zina and M.Chaabane, "A Novel fuzzy Control Strategy for Maximum Power Point Tracking of Wind Energy Conversion System", International Journal of Smart Grid, vol. 3, pp.120-127, 2019. [36] Abdelkader Harrouz; Ilhami Colak; Korhan Kayisli, "Energy Modeling Output of Wind System based on Wind Speed", 2019 8th International Conference on Renewable Energy Research and Applications (ICRERA)

[37] E. Bekiroglu; M. Duran , "Analysis of Grid Connected Wind Power System”, 2019 8th International Conference on Renewable Energy Research and Applications (ICRERA)

[38] E. Meşe, A. Bakbak, M. Ayaz, M. Boztepe, M. Altıntaş, Ö. Akın, H. Tayyer, "Development of Doubly-Fed Direct Drive Modular Permanent Magnet Wind Generator", 2019 8th International Conference on Renewable Energy Research and Applications (ICRERA)

[39] F. Ayadi, I. Colak, N. Genc, H. Ibrahim Bulbul, "Impacts of Wind Speed and Humidity on the Performance of Photovoltaic Module", 2019 8th International Conference on Renewable Energy Research and Applications (ICRERA)

[40] L. Amira; B. Tahar; M. Abdelkrim, "Sliding Mode Control of Doubly-fed Induction Generator in Wind Energy Conversion System", 2020 8th International Conference on Smart Grid (icSmartGrid)

[41] Y. Abu Eldahab, N. Saad, A. Zekry, Enhancing the maximum power point tracking techniques for photovoltaic systems. Renew Sustain Energy Rev 2014;40:505-14.

[42] ] A. Abdelkafi, L. Krichen, New strategy of pitch angle control for energy management of a wind farm. Energy 2011;36:1470-9.

[43] S. Vadi, F. Batıncan, R. Bayindir, E. Hossain, "Design and Simulation of a Grid Connected Wind Turbine with Permanent Magnet Synchronous Generator", 2020 8th International Conference on Smart Grid (icSmartGrid) 